ARTICLE

https://doi.org/10.1038/s41467-020-14848-2

\title{
Uncovering near-free platinum single-atom dynamics during electrochemical hydrogen evolution reaction
}

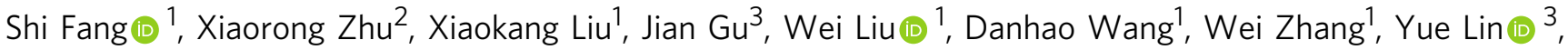
Junling Lu (iD) ${ }^{3}$, Shiqiang Wei(i) ${ }^{1}$, Yafei $\mathrm{Li}^{2} \&$ Tao Yao (i) ${ }^{1 凶}$

Single-atom catalysts offering intriguing activity and selectivity are subject of intense investigation. Understanding the nature of single-atom active site and its dynamics under working state are crucial to improving their catalytic performances. Here, we identify at atomic level a general evolution of single atom into a near-free state under electrocatalytic hydrogen evolution condition, via operando synchrotron X-ray absorption spectroscopy. We uncover that the single $\mathrm{Pt}$ atom tends to dynamically release from the nitrogen-carbon substrate, with the geometric structure less coordinated to support and electronic property closer to zero valence, during the reaction. Theoretical simulations support that the Pt sites with weakened Pt-support interaction and more $5 d$ density are the real active centers. The single-atom Pt catalyst exhibits very high hydrogen evolution activity with only $19 \mathrm{mV}$ overpotential in $0.5 \mathrm{M} \mathrm{H}_{2} \mathrm{SO}_{4}$ and $46 \mathrm{mV}$ in $1.0 \mathrm{M} \mathrm{NaOH}$ at $10 \mathrm{~mA} \mathrm{~cm}^{-2}$, and long-term durability in wide-pH electrolytes.

\footnotetext{
${ }^{1}$ National Synchrotron Radiation Laboratory, University of Science and Technology of China, Hefei 230029, P.R. China. ${ }^{2}$ Jiangsu Collaborative Innovation Centre of Biomedical Functional Materials, Jiangsu Key Laboratory of New Power Batteries, School of Chemistry and Materials Science, Nanjing Normal University, Nanjing 210023, P.R. China. ${ }^{3}$ Department of Chemical Physics, University of Science and Technology of China, Hefei 230026, P.R. China.

凶email: yaot@ustc.edu.cn
} 
T he advances in the rational design and controllable synthesis of catalysts at the atomic level have led to a booming development in the fundamental and applied researches of catalysis ${ }^{1-5}$. Recently, single-atom catalysts (SACs) that comprise isolated active metal centers have attracted considerable research interests, owing to its maximum atom efficiency and unique atomic structures and electronic properties ${ }^{6-9}$. For instance, downsizing the expensive Platinum (Pt) nanoparticle to single-atom dispersion provides an effective way to not only create cost-effective catalysts, but also improve its activity and selectivity toward several electrochemical reduction processes, such as hydrogen evolution reaction (HER), oxygen reduction reaction, nitrogen reduction reaction, and $\mathrm{CO}_{2}$ reduction reaction ${ }^{10-13}$, etc. Despite these progress, further exploration of novel SACs is still an important frontier in catalysis research, both from the aspects of materials synthesis and mechanistic understanding. To this end, an atomic-level identification of the nature of the single-atom active site is imperative so as to aid the targeted design of SACs.

For the SACs reported so far, the atomically dispersed metal atoms are usually anchored on specific substrates by chemical bonding with neighboring atoms, such as the metal-nitrogencarbon (M-N-C) materials with the trace metal and nitrogen codoped on the carbon support ${ }^{14,15}$. The catalytic activity and selectivity of SACs are highly dependent on the local coordination environment of the metal centers, in other words, the electronic and geometric interactions between the single atoms and support $^{16}$. As such, the metal-support interaction by electron transfer between single metal atom and the nearest coordination atoms will affect the charge density and distribution of metal sites, which will further impact the overall catalytic properties of the SACs ${ }^{16,17}$. The strong interaction between the single metal atom and supported N/C atoms can lead to a large charge transfer from metal to N/C atoms. Consequently, the metal atom is positively charged, presenting cation-like high-valence states. Although these high-valence metal atoms are beneficial for some electrooxidation reactions $s^{4,18,19}$, they might be unfavorable for electroreduction reactions, owing to the less $d$ electrons participating in the reaction. If the metal-support interaction becomes weak, the electronic structure of the center metal atom might resemble that of a free atom, making bonding with reactants more energetically preferred in electro-reduction reaction ${ }^{20}$. However, such free single atoms are rarely reported in the as-prepared SACs previously, mostly from the consideration of stability issue. Indeed, it has been reported that single-atom active site would undergo reconstruction in atomic configuration, accompanied by the variations in valence state, under the working conditions ${ }^{1,8,21}$. This means that the interaction between single metal atom and support would be self-adjusted in order to boost the catalytic reaction. Therefore, a deeper understanding of the working state of SACs may provide some new insights into the SACs.

Here, we report the discovery of a near-free single-atom Pt as a highly efficient active center under the electrochemical HER condition, by using operando X-ray absorption fine structure (XAFS) technique. The operando XAFS allows us to follow the structural evolutions of single-site metal centers, and unravels that the single-atom Pt becomes low-coordinated with its surrounding atoms, together with the close-to-zero valence state. As a result, the interaction between single metal atom and N-C support is weakened, leading to a near-free state of $\mathrm{Pt}$, which energetically facilitates $\mathrm{H}_{2} \mathrm{O}$ adsorption in alkaline electrolyte, followed by a more optimized $\mathrm{H}$ adsorption. As such, single-atom $\mathrm{Pt}$ anchoring on the specific site of N-C framework, accessed via the atomic layer deposition (ALD) method, exhibits the superior HER performance with ultra-low overpotentials and long-term stability in wide-pH-range electrolytes.
Structural characterization of $\mathrm{Pt}_{\mathbf{1}} / \mathrm{N}-\mathrm{C}$ single-atomic site catalyst. We synthesized atomically dispersed Pt on a metal-organic framework (MOF) derived $\mathrm{N}-\mathrm{C}$ framework (sample designated as $\mathrm{Pt}_{1} / \mathrm{N}-\mathrm{C}$ ) using ALD. It is noted that each carbon ring of Uio-66$\mathrm{NH}_{2}$ anchors one $-\mathrm{NH}_{2}$ group, and the $-\mathrm{NH}_{2}$-derived uncoordinated $\mathrm{N}$ site may act as the anchoring site for $\mathrm{Pt}$ atom during the ALD process (Supplementary Fig. 1). The combination of welldefined MOF structure and ALD technique helps atomic-level precise deposition of single-atom Pt on the specific N-C site with nearly uniform local coordination environments. The atomicresolution scanning transmission electron microscopy (STEM) performed in high-angle annular dark field (HAADF) mode show that most Pt species are isolated and uniformly dispersed on the $\mathrm{N}-\mathrm{C}$ substrate (bright spots corresponding to single-atom $\mathrm{Pt}$ ) (Fig. 1a). The STEM-coupled energy-dispersive spectroscopy (EDS) element mapping further corroborates the presence of C, $\mathrm{N}$, and Pt elements, and the homogeneous distribution of $\mathrm{Pt}$ throughout the octahedral-shaped sample (Fig. 1b). The singlePt-atom site was further supported by $\mathrm{CO}$-absorbed diffuse reflectance infrared Fourier transform spectroscopy (CODRIFTS). As shown in Supplementary Fig. 2a, the narrow and quasi-symmetrical band at $\sim 2084 \mathrm{~cm}^{-1}$, which remain unchanged during $\mathrm{CO}$ desorption, can be ascribed to linearly adsorbed $\mathrm{CO}$ on single-atom Pt. For comparison, we synthesized $\mathrm{Pt}$ nanoparticles (Pt-NPs) by treating the $\mathrm{Pt}_{1} / \mathrm{N}-\mathrm{C}$ in a $20 \% \mathrm{H}_{2} / \mathrm{Ar}$ flow at $300^{\circ} \mathrm{C}$ (Supplementary Fig. 3). The CO-DRIFTS spectra of Pt-NPs exhibit a redshift of the IR peak from 2058 to $2052 \mathrm{~cm}^{-1}$ (Supplementary Fig. 2b) during CO desorption, which correlate with changes in dipole-dipole coupling between $\mathrm{CO}$ on the surface of Pt crystal ${ }^{22-25}$. Pt content in $\mathrm{Pt}_{1} / \mathrm{N}-\mathrm{C}$ is $\sim 2.5 \mathrm{wt} \%$ as determined by the coupled plasma optical emission spectrometry (ICP-OES) analysis. Note that when using the Uio-66 derived C framework as the substrate, small Pt clusters are formed (Supplementary Fig. 4) under the same ALD process, confirming that the uncoordinated $\mathrm{N}$ atoms in the N-C framework provide essential sites for immobilizing single-atom $\mathrm{Pt}^{3,26,27}$. Furthermore, Pt-N coordination can be confirmed by $\mathrm{N}$ K-edge X-ray absorption spectroscopy and N1s X-ray photoelectron spectroscopy results (Fig. 1c and Supplementary Fig. 5). The N K-edge absorption spectrum of pure $\mathrm{N}-\mathrm{C}$ framework without Pt can be characterized by four nitrogen features: pyridinic (peak a, $398.5 \mathrm{eV}$ ), pyrrolic (peak b, $399.4 \mathrm{eV}$ ), graphitic (peak c, $401.6 \mathrm{eV}$ ), and C-N-C or C-N $\sigma^{\star}$ bond (peak d, $407.3 \mathrm{eV}$ ), respectively ${ }^{28-30}$. After Pt deposition, the pyrrolic peak b remains constant, whereas the pyridinic peak a is damped and split into two peaks $\left(a_{1}\right.$ and $\left.a_{2}\right)$, where $a_{2}$ is derived from a portion of pyridinic $\mathrm{N}$ bonded to Pt atoms, in accordance with the previous reports $^{31,32}$.

Operando X-ray absorption spectroscopy study. To reveal the nature of the single-Pt-atom site under electro-reduction working conditions, the operando XAFS measurements using a purposebuilt cell were performed on $\mathrm{Pt}_{1} / \mathrm{N}-\mathrm{C}$ catalyst during HER. Carbon cloth was used as the working electrode for loading catalyst, together with $\mathrm{Ag} / \mathrm{AgCl}$ reference electrode and carbon rod counter electrode in an electrochemical cell (Supplementary Fig. 6). As shown in Supplementary Fig. 7, the catalysts were homogeneously adhered in the gap of the carbon fibers without obvious aggregation, meaning that the catalysts may be fully exposed to the electrolyte so that subtle variations of the Pt active sites can be discerned.

Figure $1 \mathrm{~d}$ shows the evolutions of normalized $\mathrm{Pt}_{2}$-edge $\mathrm{X}$-ray absorption near-edge structure (XANES) spectra with applied potential. The XANES spectrum of catalyst is characterized by the strong white-line peak, which corresponds to transition from the 

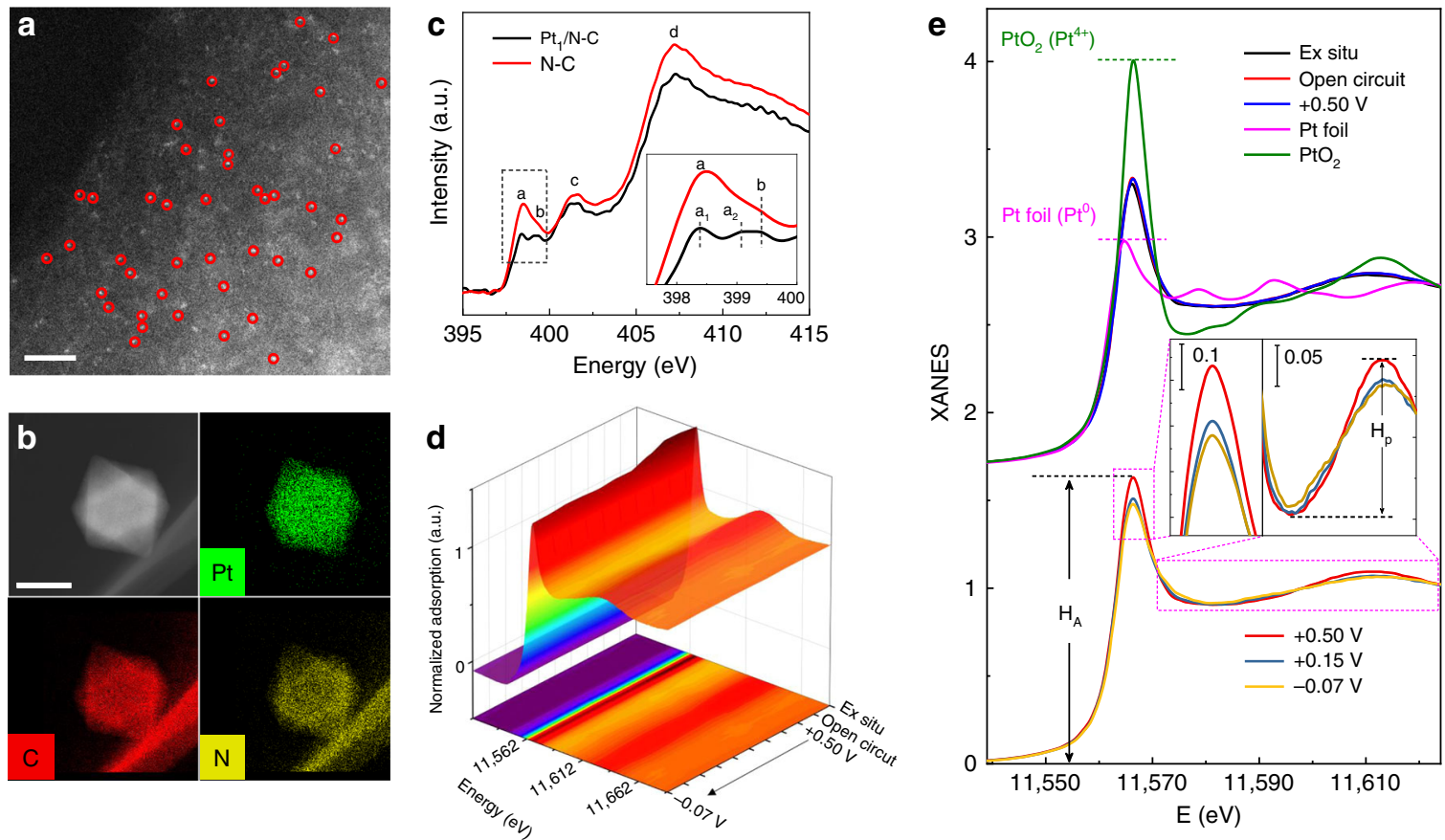

Fig. 1 Microstructure and operando XANES characterization. a Atomic-resolution HAADF-STEM image of $\mathrm{Pt}_{1} / \mathrm{N}-\mathrm{C}$, showing that only $\mathrm{Pt}$ single atoms are present (marked by red circles). Length of scale bar is $2 \mathrm{~nm}$. b Micromorphology and elemental mapping of Pt/ $/ \mathrm{N}-\mathrm{C}$. Length of scale bar is $200 \mathrm{~nm}$. c N Kedge XANES spectra of N-C framework (before ALD) and $\mathrm{Pt}_{1} / \mathrm{N}-\mathrm{C}$ (after ALD). d Three-dimensional profile plot of successive operando Pt $\mathrm{L}_{3}$-edge $\mathrm{XANES}$ spectra acquired in different conditions. e Selected XANES spectra in $\mathbf{d}$ at different applied voltages from the open-circuit condition to $-0.07 \mathrm{~V}$ during $\mathrm{HER}$, and the XANES data of the reference standards of $\mathrm{Pt}$ foil and $\mathrm{PtO}_{2}$. Inset, Magnified white-line peak and post-edge XANES region.

occupied Pt $2 p_{3 / 2}$ core-electron to empty $5 d$ states, and thus is indicative of $5 d$-band occupancy ${ }^{33,34}$. It can be obviously discerned that the overall white-line intensity $\left(\mathrm{H}_{\mathrm{A}}\right)$ decreases as applying negative potential during the reaction (Fig. 1d). Specifically, the white-line intensities of the catalyst under ex situ, open circuit and $+0.5 \mathrm{~V}$ (vs. RHE, all voltages mentioned hereafter are normalized to RHE scale) conditions remain unchanged (Fig. 1e), suggesting that the single-atom $\mathrm{Pt}$ site is structurally stable without chemical adsorption of reactant species in the electrolyte. This is reasonable as $+0.5 \mathrm{~V}$ is commonly considered as located in the double layer region where only capacitive charging process occurs on the electrode surface without any redox reaction ${ }^{35,36}$. When the applied potential negatively shifts to $+0.15 \mathrm{~V}$ and to $-0.07 \mathrm{~V}$, the white-line intensity gradually decreases, indicating a higher $5 d$ occupancy of Pt. Here, the unoccupied $5 d$ states mainly arise from the hybridization between $\mathrm{Pt}$ and nearby $\mathrm{C} / \mathrm{N}$ atoms from support. Hence, higher $5 d$ occupancy implies the less charge transfer from the single-atom $\mathrm{Pt}$ to the nearby $\mathrm{C} / \mathrm{N}$ atoms at $+0.15 \mathrm{~V}$ and $-0.07 \mathrm{~V}$.

To obtain the quantitative information of electronic structural evolutions, we examine the valence state and formal $d$-band holes count of Pt. The above-described variations can be described

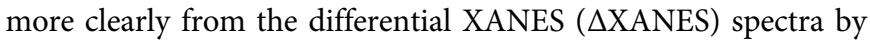
subtracting the spectra collected at different potentials from that of $\mathrm{Pt}$ foil reference (Supplementary Fig. 8). The valence states and formal $d$-band hole counts of Pt can be determined quantitatively by integrating the area of the white-line peak in the $\triangle$ XANES spectra. It can be found that the mean valence state of $\mathrm{Pt}$ decreases from 1.89 to 1.17 and 1.12 for the catalyst at the potentials from $+0.5 \mathrm{~V}$ to $+0.15 \mathrm{~V}$ and $-0.07 \mathrm{~V}$ (Fig. 2b), respectively, implying that the $\mathrm{Pt}$ site is reduced close-to-zero valence toward the metallic state. The formal $d$-band hole count was estimated using a slope of 1.174 unit area per $d$-band hole obtained from $\mathrm{Pt}^{0}$ foil $\left(5 \mathrm{~d}^{9} 6 \mathrm{~s}^{1}\right)$ and $\mathrm{Pt}^{\mathrm{IV}} \mathrm{O}_{2}\left(5 \mathrm{~d}^{6} 6 \mathrm{~s}^{0}\right)$ standards. The absolute number of $d$-band holes for the ex situ $\mathrm{Pt}_{1} / \mathrm{N}-\mathrm{C}$ is 2.420, which is reduced to 1.877 and 1.838 for the $\mathrm{Pt}_{1} / \mathrm{N}-\mathrm{C}$ under
$+0.15 \mathrm{~V}$ and $-0.07 \mathrm{~V}$ (Fig. 2a), suggesting the increased $d$-band electrons of $\mathrm{Pt}$, verifying the weaker interaction between the $\mathrm{Pt}$ and the N-C substrate under working states.

The evolution of coordination configuration of single-atom $\mathrm{Pt}$ was further identified by extended X-ray absorption fine structure (EXAFS) (Supplementary Fig. 9 and 10). The Fouriertransformed (FT) $k^{2}$-weighted EXAFS spectra for $\mathrm{Pt}_{1} / \mathrm{N}-\mathrm{C}$ at the corresponding applied potentials all present a single dominant peak at ca. $1.6 \AA$ that can be assigned to the coordination between $\mathrm{Pt}$ atom and C/N/O light atoms. However, the intensity of FT peak damps by $\sim 13$ and $35 \%$ when the applied potentials negatively shift from $+0.5 \mathrm{~V}$ to $+0.15 \mathrm{~V}$ and to $-0.07 \mathrm{~V}$ (Fig. 2c), respectively, suggesting the distinct variations of the local geometric structure of $\mathrm{Pt}$ site under working conditions. The geometric variations can also be reflected by the increased structural disorder, as revealed from the features in the XANES post-edge plateau corresponding to the interference of photoelectrons with local atoms. As shown in Fig. 1e inset, the intensity of the oscillation hump $\left(\mathrm{H}_{\mathrm{P}}\right)$ decreases with the increased potential, confirming dynamically disordered structures around the Pt atom ${ }^{33}$. Note that the above evolutions of the atomic and electronic structures are reversible as demonstrated in Supplementary Fig. 11 and 12.

Then, we would like to reveal the detail evolutions of geometric configuration of single-Pt site. To first confirm the geometric structure of the ex situ state, we performed EXAFS curve fitting considering two backscattering paths of $\mathrm{Pt}-\mathrm{C}$ and $\mathrm{Pt}-\mathrm{N}$ from $\mathrm{N}$ $\mathrm{C}$ framework, for the $\mathrm{Pt}_{1} / \mathrm{N}-\mathrm{C}$ under ex situ, open-circuit, and $+0.5 \mathrm{~V}$ conditions (Fig. 2c and Supplementary Fig. 13). The best fitting analyses give four coordination number of $\mathrm{Pt}-\mathrm{C} / \mathrm{N}$ (Supplementary Table 1). Considering the limit of XAFS in differentiating $\mathrm{Pt}-\mathrm{C}$ and $\mathrm{Pt}-\mathrm{N}$ coordination because of the close scattering amplitude of $\mathrm{C}$ and $\mathrm{N}$, we resort to the density functional theory (DFT) calculations considering several configurations, including $\mathrm{Pt}_{1}-\mathrm{C}_{3} \mathrm{~N}_{1}, \mathrm{Pt}_{1}-\mathrm{C}_{2} \mathrm{~N}_{2}$, and $\mathrm{Pt}_{1}-\mathrm{C}_{1} \mathrm{~N}_{3}$ 

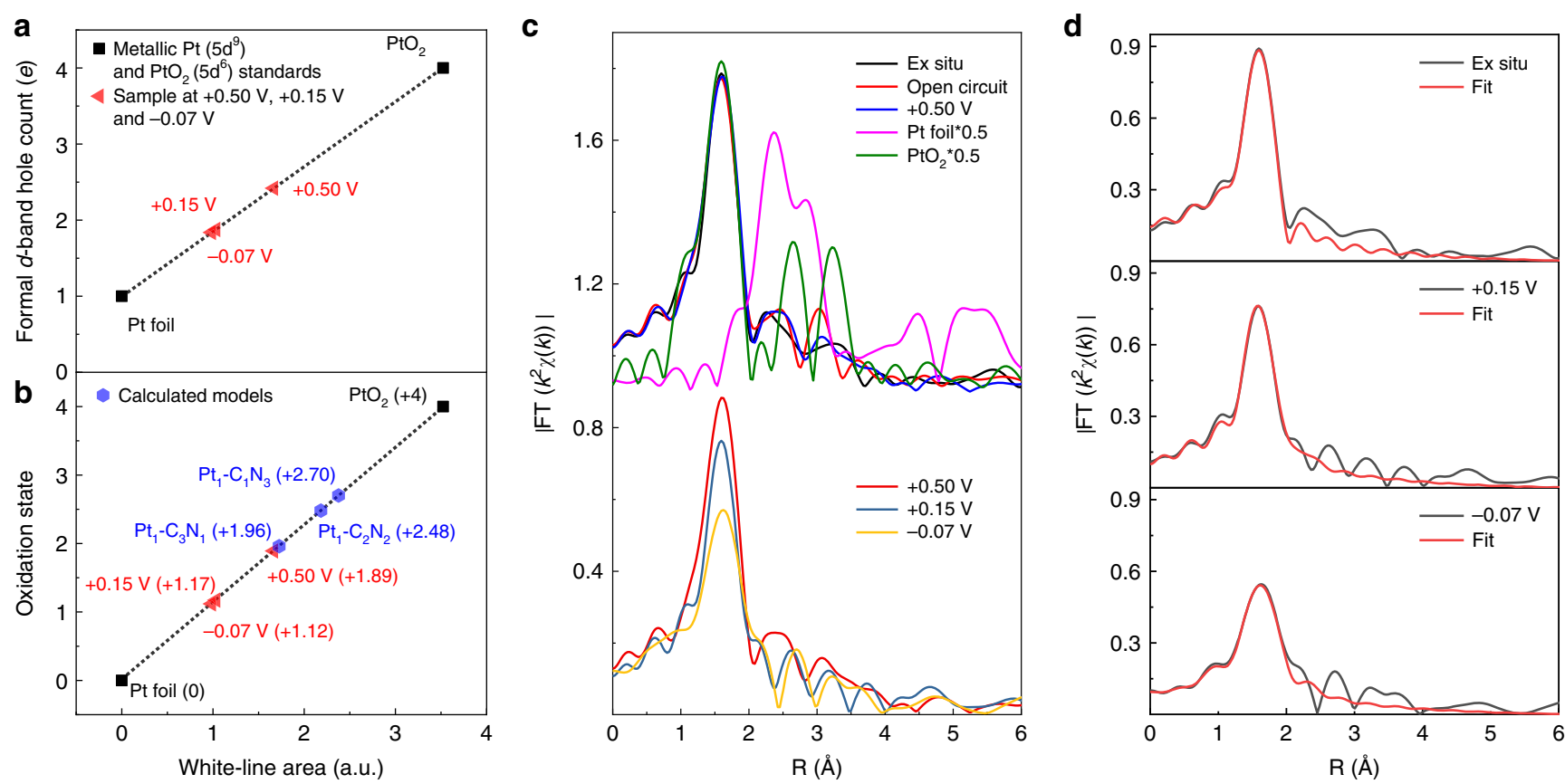

Fig. 2 Operando EXAFS and $\triangle$ XANES characterization. a The fitted average formal $d$-band hole counts and $\mathbf{b}$ oxidation states of Pt from $\triangle X A N E S$ spectra, depicted with the calculated oxidation states of $\mathrm{Pt}_{1}-\mathrm{C}_{3} \mathrm{~N}_{1}, \mathrm{Pt}_{1}-\mathrm{C}_{2} \mathrm{~N}_{2}$, and $\mathrm{Pt}_{1}-\mathrm{C}_{1} \mathrm{~N}_{3}$ models. The oxidation state of $\mathrm{Pt}_{1}-\mathrm{C}_{3} \mathrm{~N}_{1}$ are the most proximate to that of the ex situ sample. c Corresponding $k^{2}$-weighted Fourier transform (FT) spectra of Fig. 1e. $\mathbf{d}$ First-shell fitting of EXAFS spectra under ex situ, $+0.15 \mathrm{~V}$ and $-0.07 \mathrm{~V}$ conditions.

(Supplementary Fig. 14). Quantitatively, the $\mathrm{Pt}$ atom donates 0.47, 0.59 and $0.64 e$ to the support in $\mathrm{Pt}_{1}-\mathrm{C}_{3} \mathrm{~N}_{1} \mathrm{Pt}_{1}-\mathrm{C}_{2} \mathrm{~N}_{2}$, and $\mathrm{Pt}_{1}-\mathrm{C}_{1} \mathrm{~N}_{3}$, respectively (where $e$ is the elementary charge) (Supplementary Table 2). The corresponding oxidation states of Pt estimated by normalizing Bader charges (see Supplementary Note 2) are 1.96 to 2.48 and 2.70 for $\mathrm{Pt}_{1}-\mathrm{C}_{3} \mathrm{~N}_{1}, \mathrm{Pt}_{1}-\mathrm{C}_{2} \mathrm{~N}_{2}$, and $\mathrm{Pt}_{1}$ $\mathrm{C}_{1} \mathrm{~N}_{3}$, respectively (Fig. $2 \mathrm{~b}$ and Supplementary Note 2). Hence, the calculated $\mathrm{Pt}$ valence state of $\mathrm{Pt}_{1}-\mathrm{C}_{3} \mathrm{~N}_{1}$ (1.96) is more close to that (1.89) derived from XANES analyses. Based on these considerations, the best EXAFS fitting gives three Pt-C bonds $(R=2.04 \AA)$ and one Pt-N bond $(R=2.09 \AA)$ (Supplementary Table 1). Moreover, structures containing more than one Pt-N coordination, i.e., $\mathrm{Pt}_{1}-\mathrm{C}_{2} \mathrm{~N}_{2}$, and $\mathrm{Pt}_{1}-\mathrm{C}_{1} \mathrm{~N}_{3}$ can be reasonably excluded since it is unlikely for one $\mathrm{Pt}$ bridging two $\mathrm{N}$ atoms with $\mathrm{N}-\mathrm{N}$ distance of ca. $10 \AA$ between two adjacent $\mathrm{N}$ atoms in Uio$66-\mathrm{NH}_{2}$.

Interestingly, for the catalyst under $+0.15 \mathrm{~V}$, the $\mathrm{Pt}-\mathrm{C} / \mathrm{N}$ coordination number reduced to 2 , together with the appearance of one additional Pt-O coordination $(R=2.06 \AA$ ) (Fig. $2 \mathrm{~d}$ and Supplementary Fig. 15), which is possibly arisen from the adsorption of the oxygen-related group from $\mathrm{H}_{2} \mathrm{O}$ or $\mathrm{OH}^{-}$. Considering that $\mathrm{OH}^{-}$adsorption should occur in a more positive potential region of $0.65 \sim 0.85 \mathrm{~V}^{35}$, and in alkaline HER, the catalytic cycle is initiated by adsorption of $\mathrm{H}_{2} \mathrm{O}$ onto the active site. Hence, we can conclude that the $\mathrm{Pt}-\mathrm{O}$ coordination can be ascribed to adsorption of $\mathrm{H}_{2} \mathrm{O}$ molecules. This is also consistent with the rate limitation step of dissociation of the absorbed $\mathrm{H}_{2} \mathrm{O}$ at this stage. The reduced coordination number of $\mathrm{Pt}$ with support indicate that $\mathrm{Pt}$ atoms are released from support, this effect we consider is beneficial for the adsorption of $\mathrm{H}_{2} \mathrm{O}$ molecules. Furthermore, only twofold $\mathrm{Pt}-\mathrm{C} / \mathrm{N}$ coordination was obtained for the catalyst at $-0.07 \mathrm{~V}$, where the water is dissociated into $\mathrm{OH}^{-}$and adsorbed $\mathrm{H}^{*}$, followed by the attack of another proton to generate $\mathrm{H}_{2}$. However, $\mathrm{Pt}-\mathrm{H}$ coordination can hardly be discerned, owing to the small scattering amplitude of $\mathrm{H}^{37}$. Hence, only twofold $\mathrm{Pt}-\mathrm{C} / \mathrm{N}$ coordination is considered in the EXAFS fitting (Fig. 2d and Supplementary Fig. 16). These coordinative evolutions of $\mathrm{Pt}$ can be further confirmed by the wavelet transform analysis, as shown in Supplementary Fig. 17.

We want to note that these findings of near-free Pt state during electro-reduction reaction hold true in wide- $\mathrm{pH}$ environments. As shown in Supplementary Fig. 18, the operando XAFS measurements were also carried out in $0.1 \mathrm{M} \mathrm{HClO}_{4}(\mathrm{pH}=1)$ and $1.0 \mathrm{M} \mathrm{NaOH}(\mathrm{pH}=14)$ under the applied potential of $+0.15 \mathrm{~V}$. The variation trends of XANES and EXAFS spectra in $\mathrm{pH} 1$ and $\mathrm{pH} 14$ are analogous to those in $\mathrm{pH} 13$, showing the significantly reduced intensities of white-line peak and FT peak. Through the quantitative analyses, we demonstrate that the single-atom $\mathrm{Pt}$ resemble the free atom during HER, with low coordination to the support and the valence state close to zero. We reckon that such evolutions of the single-Pt sites might directly boost the HER in wide- $\mathrm{pH}$ electrolytes.

Theoretical simulations. Theoretical investigations based on DFT calculations were carried out to unravel the influences of the evolved configurations on the electronic structure. According to the above EXAFS fitting models, two possible and stable twocoordinate configurations, i.e., $\mathrm{Pt}_{1}-\mathrm{C}_{2}$ and $\mathrm{Pt}_{1}-\mathrm{C}_{1} \mathrm{~N}_{1}$, were constructed for simulating the varied $\mathrm{Pt}$ local structure under realistic reaction, as shown in Fig. 3a. On the basis of Bader charge analysis, the charge transfer from the $\mathrm{Pt}$ atom to support is only ca. $0.1 \sim 0.2 e$ for the $\mathrm{Pt}_{1}-\mathrm{C}_{2}$ and $\mathrm{Pt}_{1}-\mathrm{C}_{1} \mathrm{~N}_{1}$, much smaller than $0.47 e$ for $\mathrm{Pt}_{1}-\mathrm{C}_{3} \mathrm{~N}_{1}$ (Supplementary Table 2). As such, the $\mathrm{Pt}$-support interactions of the two-coordinate models are much weaker than that of the ex situ $\mathrm{Pt}_{1}-\mathrm{C}_{3} \mathrm{~N}_{1}$ model.

Based on the models in Fig. 3a, we then explore the potential HER activity of less-coordinate $\mathrm{Pt}_{1}-\mathrm{C}_{2}$ and $\mathrm{Pt}_{1}-\mathrm{C}_{1} \mathrm{~N}_{1}$ sites. The overall HER pathway can be described by a three-state diagram comprising the initial catalyst-water state, to the catalyst- $\mathrm{H}$ intermediate state, and the final catalyst $+\mathrm{H}_{2}$ state. The Gibbs free-energy of atomic hydrogen adsorption, $\left|\Delta G_{\mathrm{H}^{*}}\right|$, has been 
a

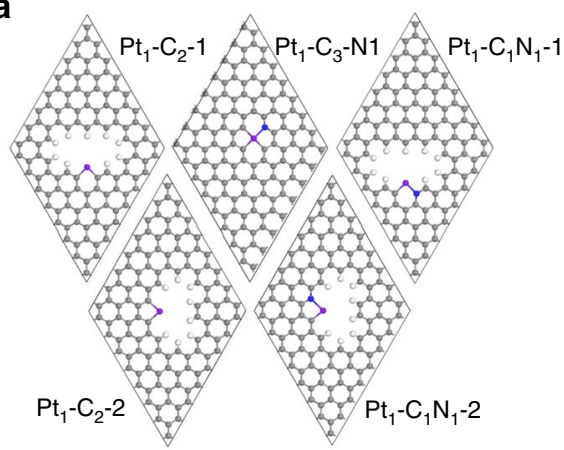

b

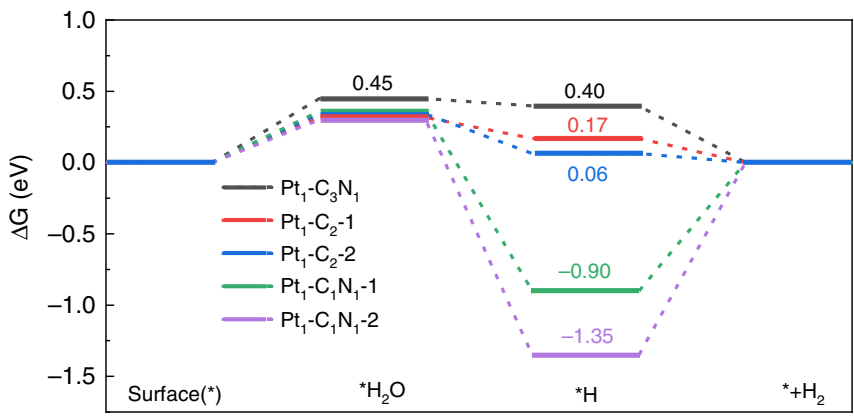

C
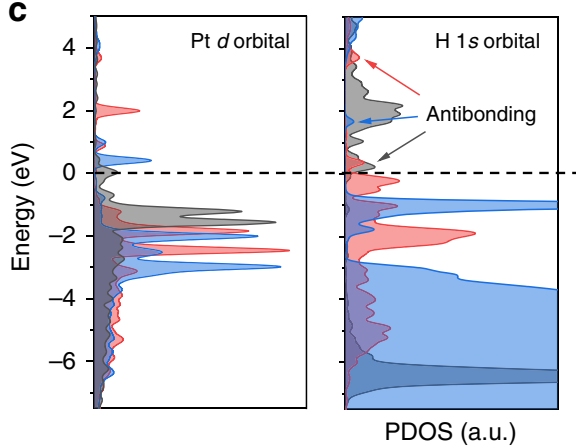

Reaction coordinate

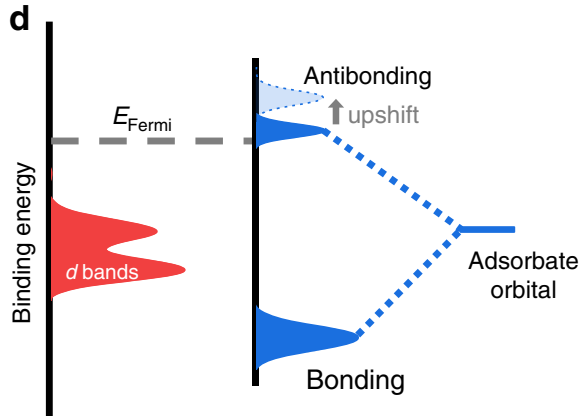

Fig. 3 Theoretical investigations. a Computational models of the $\mathrm{Pt}_{1}-\mathrm{C}_{3} \mathrm{~N}_{1}$ and two $\mathrm{Pt}_{1}-\mathrm{C}_{2}$ and two $\mathrm{Pt}_{1}-\mathrm{C}_{1} \mathrm{~N}_{1}$ moieties. $\mathrm{H}$, white; $\mathrm{C}$, gray; $\mathrm{N}$, blue; $\mathrm{Pt}$, purple. b Calculated adsorption energies of $\mathrm{H}_{2} \mathrm{O}$ and $\mathrm{H}$ on the surface of $\mathrm{Pt}_{1}-\mathrm{C}_{3} \mathrm{~N}_{1}, \mathrm{Pt}_{1}-\mathrm{C}_{2}$ and $\mathrm{Pt}_{1}-\mathrm{C}_{1} \mathrm{~N}_{1}$. c Calculated PDOS of Pt $d$ orbital of clean surfaces, $\mathrm{H} 1 \mathrm{~s}$ of hydrogen adsorbed on Pt sites and Pt $d$ of Pt sites with adsorbed hydrogen (denoted *Pt $d$ orbital), from left to right, respectively. The gray, red and blue contour represent $\mathrm{Pt}_{1}-\mathrm{C}_{3} \mathrm{~N}_{1}, \mathrm{Pt}_{1}-\mathrm{C}_{2}-1$, and $\mathrm{Pt}_{1}-\mathrm{C}_{2}-2$ surfaces, respectively. The DOS peaks of $\mathrm{H} 1 \mathrm{~s}-\mathrm{Pt} 5 d$ antibonding are indicated by the arrows. Note that the sharp peak $\sim-1 \mathrm{eV}$ for $\mathrm{Pt}_{1}-\mathrm{C}_{2}-2$ represent bonding rather than antibonding state, as it corresponds to the prominent $\mathrm{Pt} d$ band in the ${ }^{\star} \mathrm{Pt} d \mathrm{PDOS}$. d Schematic DOS illustration of the interaction between $\mathrm{Pt}$ and $\mathrm{H}$, the $\mathrm{H} 1 \mathrm{~s}$ states split into bonding and antibonding states. With four-coordinate Pt evolving to two-coordinate, the corresponding antibonding states upshift to a higher energy with a lower occupancy.

considered as a reasonable descriptor of the HER activity. As is known, Pt shows the optimal level for $\mathrm{H}$ adsorption step with a near-zero $\Delta G_{\mathrm{H}^{*}}$ (ca. $\left.0.09 \mathrm{eV}\right)$, owing to its suitable $d$-band position ${ }^{38,39}$. As shown in Fig. $3 b$, the $\Delta G_{\mathrm{H}^{*}}$ of the two $\mathrm{Pt}_{1}-\mathrm{C}_{2}$ sites $(0.17$ and $0.06 \mathrm{eV})$ are closer to $0 \mathrm{eV}$, compared to that of ex situ $\mathrm{Pt}_{1}-\mathrm{C}_{3} \mathrm{~N}_{1}$ site $(0.40 \mathrm{eV})$. Moreover, both $\mathrm{Pt}_{1}-\mathrm{C}_{1} \mathrm{~N}_{1}$ sites exhibit significantly larger $\left|\Delta G_{\mathrm{H}^{*}}\right|$, meaning that hydrogen adsorption on $\mathrm{Pt}_{1}-\mathrm{C}_{1} \mathrm{~N}_{1}$ sites are too strong to desorb. The DFT analyses, in combination with the above XANES, indicate that the $\mathrm{Pt}$ in $\mathrm{Pt}_{1}-\mathrm{C}_{2}$ sites have more $5 d$ densities close to freeatom $\mathrm{Pt}$, leading to a more favorable $\mathrm{H}^{\star}$ adsorption, thus facilitating the HER in acid condition. For the HER in an alkaline media, the water dissociation kinetics from the Volmer step may determine the overall reaction rate. The DFT calculations show that the water adsorption on the two-coordinate sites is more favorable than that on the $\mathrm{Pt}_{1}-\mathrm{C}_{3} \mathrm{~N}_{1}$ site, as the $\mathrm{H}_{2} \mathrm{O}$ adsorption energy decrease from $0.45 \mathrm{eV}$ to $0.3 \sim 0.35 \mathrm{eV}$ (Fig. 3b).

Above analysis on adsorption energy demonstrates that hydrogen adsorption on $\mathrm{Pt}_{1}-\mathrm{C}_{2}$ sites is significantly improved comparing with that on $\mathrm{Pt}_{1}-\mathrm{C}_{3} \mathrm{~N}_{1}$ site. To investigate the underlying reason, we carried out partial density of state (PDOS) analysis (Supplementary Fig. 19 and Fig. 3c). The dominant $d$ band features $(-1 \sim-3.5 \mathrm{eV})$ of the three surfaces are nearly degenerate, compared to the broad $d$ band of bulk Pt (Supplementary Fig. 19). The $d$ band positions of both $\mathrm{Pt}_{1}-\mathrm{C}_{2}$ are lower than that of $\mathrm{Pt}_{1}-$ $\mathrm{C}_{3} \mathrm{~N}_{1}$, indicating weaker $\mathrm{Pt}$-support interaction. Besides, an obvious peak appears near the Fermi level $(0 \mathrm{eV})$ for the $\mathrm{Pt}_{1^{-}}$ $\mathrm{C}_{3} \mathrm{~N}_{1}$ surface (Supplementary Fig. 19, pointed by arrows), suggesting relatively strong hybridization between $\mathrm{Pt}$ and $\mathrm{C} / \mathrm{N}$ orbitals and reflecting strong bindings between $\mathrm{Pt}$ atoms and substrates. In contrast, the $\mathrm{Pt}$ sites of both two $\mathrm{Pt}_{1}-\mathrm{C}_{2}$ structures provide much smaller DOS at the Fermi level, further verifying the weakened $\mathrm{Pt}$-support interaction, meaning that $\mathrm{Pt}$ atoms become freer from the supports under reaction conditions. We consider that such near-free Pt with more $5 d$ density and low-valence state is favorable for the adsorption of $\mathrm{H}_{2} \mathrm{O}$ and $\mathrm{H}$ reactants. This can be confirmed by the DOS of the $\mathrm{Pt}_{1}-\mathrm{C}_{3} \mathrm{~N}_{1}$ and $\mathrm{Pt}_{1}-\mathrm{C}_{2}$ surfaces (Supplementary Fig. 20). Compared with $\mathrm{Pt}_{1}-\mathrm{C}_{3} \mathrm{~N}_{1}$, the prominent peaks of $\mathrm{Pt}_{1}-\mathrm{C}_{2}$ surfaces at the Fermi level imply higher localized electron density on $\mathrm{Pt}$ site, which may benefit the activation of $\mathrm{H}_{2} \mathrm{O}$ molecules and thus boosts HER activity.

Moreover, we consider the cases of a hydrogen atom adsorbed on the $\mathrm{Pt}_{1}-\mathrm{C}_{3} \mathrm{~N}_{1}$ and two $\mathrm{Pt}_{1}-\mathrm{C}_{2}$ surfaces, and calculate the corresponding DOS projected onto the $\mathrm{H} 1 s$ states and $\mathrm{Pt} d$ bands (Fig. $3 \mathrm{c}$, the middle and right panels). In the $\mathrm{H} 1 s$ PDOS, the dominant features are the $\mathrm{H} 1 s$-Pt $5 d$ bonding resonances below the Fermi level, distinct in energy position and intensity for three different surfaces. In particular, the antibonding states are all above the Fermi level but in different energy position (noted by the arrows), by which the occupancy of antibonding states can be discerned. For instance, the antibonding states of $\mathrm{Pt}_{1}-\mathrm{C}_{3} \mathrm{~N}_{1}$ is close to Fermi level, meaning a relative high occupancy. Although both $\mathrm{Pt}_{1}-\mathrm{C}_{2}-1$ and $\mathrm{Pt}_{1}-\mathrm{C}_{2}-2$ show higher energy position of antibonding, indicating lower antibonding occupancy and less repulsive interaction between $\mathrm{H} 1 s$ and $\mathrm{Pt} 5 d$ orbitals, leading to the stronger $\mathrm{Pt}-\mathrm{H}$ interaction. Note that the antibonding position of $\mathrm{Pt}_{1}-\mathrm{C}_{2}-2$ is lower than that of $\mathrm{Pt}_{1}-\mathrm{C}_{2}-1$, but the bonding state intensity of $\mathrm{Pt}_{1}-\mathrm{C}_{2}-2$ is much higher than that of $\mathrm{Pt}_{1}-\mathrm{C}_{2}-1$, resulting in a stronger hydrogen adsorption on $\mathrm{Pt}_{1}-\mathrm{C}_{2}-2$, consistent with the $\Delta G_{\mathrm{H}^{*}}$ values. 
Figure $3 \mathrm{~d}$ shows schematic illustration of the interaction between $\mathrm{Pt} 5 d$ and $\mathrm{H} 1 s$ orbitals. When the hydrogen adsorbate hybridizes with the $d$ band of $\mathrm{Pt}$, the adsorbate state split into localized bonding and antibonding states. The higher position of the antibonding, the stronger $\mathrm{Pt}-\mathrm{H}$ interaction. Based on the above analysis, we reckon that with the evolution of Pt site from four-coordinate to two-coordinate, the antibonding states upshift to higher energy position, leading to lower occupancy and consequent stronger hydrogen adsorption. Hence, the theoretical insights emphasize the importance of the evolution of electronic and atomic structures of Pt into a near-free state under the electro-reduction potentials for the high HER activity.

Electrochemical characterization. Combining operando XAFS characterization and DFT calculation, we reveal for the first time that the single-atom Pt tend to evolve into a more freestanding state, which can substantially boost HER in both preferred water adsorption and moderate hydrogen adsorption. Thus, the electrocatalytic HER activities of $\mathrm{Pt}_{1} / \mathrm{N}-\mathrm{C}$ was examined in wide-pH electrolytes, including $1.0 \mathrm{M} \mathrm{KOH}$ and $0.5 \mathrm{M} \mathrm{H}_{2} \mathrm{SO}_{4}$ solutions. For comparison, the HER performance of the pristine $\mathrm{N}-\mathrm{C}$ substrate and commercial $20 \% \mathrm{Pt} / \mathrm{C}$ were also measured under the same test conditions. As shown in Fig. 4a, at the current density of $10 \mathrm{~mA} \mathrm{~cm}^{-2}$, the $\mathrm{Pt}_{1} / \mathrm{N}-\mathrm{C}$ delivers a very small overpotential of 46 and $19 \mathrm{mV}$ in alkaline and acid solution, respectively, superior to those of $\mathrm{Pt} / \mathrm{C}$ ( 57 and $25 \mathrm{mV}$ ). In contrast, the pristine $\mathrm{N}-\mathrm{C}$ substrate exhibits negligible HER activity in both acid and alkaline, as the current densities of $\mathrm{N}-\mathrm{C}$ are close to zero, confirming that the high HER activity of $\mathrm{Pt}_{1} / \mathrm{N}-\mathrm{C}$ is contributed by the singleatom Pt sites. Notably, the Tafel slope of $\mathrm{Pt}_{1} / \mathrm{N}-\mathrm{C}$ in $1.0 \mathrm{M} \mathrm{KOH}$ is $36.8 \mathrm{mV} \mathrm{dec}^{-1}$, lower than that of $\mathrm{Pt} / \mathrm{C}\left(39.8 \mathrm{mV} \mathrm{dec}^{-1}\right)$, indicating the Volmer-Heyrovsky mechanism as the HER pathway ${ }^{39}$.
The Tafel slope of $\mathrm{Pt}_{1} / \mathrm{N}-\mathrm{C}\left(14.2 \mathrm{mV} \mathrm{dec}^{-1}\right)$ in $0.5 \mathrm{M} \mathrm{H}_{2} \mathrm{SO}_{4}$ is also comparable to that of $\mathrm{Pt} / \mathrm{C}\left(18.6 \mathrm{mV} \mathrm{dec}^{-1}\right)$ (Fig. $\left.4 \mathrm{~b}\right)$. The result of HER catalyzing stability test is present in Fig. 4c, which shows negligible loss of current density in both acid and alkaline electrolytes in 20 hours, demonstrating excellent long-time durability of the $\mathrm{Pt}_{1} / \mathrm{N}-\mathrm{C}$ catalysts. Also, the single-atom structure and dispersion are preserved, as can be confirmed by the electron microscopic and XAFS measurements for the $\mathrm{Pt}_{1} / \mathrm{N}-\mathrm{C}$ catalyst after the long-time HER test (Supplementary Fig. 21). Moreover, the turnover frequencies (TOFs) of $\mathrm{Pt}_{1} / \mathrm{N}-\mathrm{C}$ are 22.07 and $1.89 \mathrm{H}_{2} \mathrm{~s}^{-1}$ in acid and alkaline, 10 and 12 times higher than those of $\mathrm{Pt} / \mathrm{C}$, respectively (Fig. $4 \mathrm{~d}$ ). To the best of our knowledge, the HER performances in the wide-pH electrolytes of our $\mathrm{Pt}_{1} / \mathrm{N}$ $\mathrm{C}$ catalyst are almost the best among the SACs reported recently, as summarized in Supplementary Table 3. These results confirm that the $\mathrm{Pt}_{1} / \mathrm{N}-\mathrm{C}$ possesses the best intrinsic HER activity that is mainly contributed by the reconstructed single-Pt sites.

\section{Discussion}

On the basis of the operando XAFS, we identify the atomic and electronic structural evolutions of the single-atom Pt site under electrochemical HER. We uncover that the Pt atom tends to be a near-free state resembling a free metallic atom, that is, the interaction and charge transfer between $\mathrm{Pt}$ and $\mathrm{N}-\mathrm{C}$ support is weakened. Theoretical simulations support that the near-free single-atom Pt possesses the favorable bonding energies with the reactants, responsible for the superior HER activity. Our study highlights the importance of creating more free single metal atoms while remaining stable for boosting the electrochemical reduction reactions. These findings also suggest a new insight into tailoring the coordination environment of single-atom active sites for developing high-performance single-atom electrocatalyst.
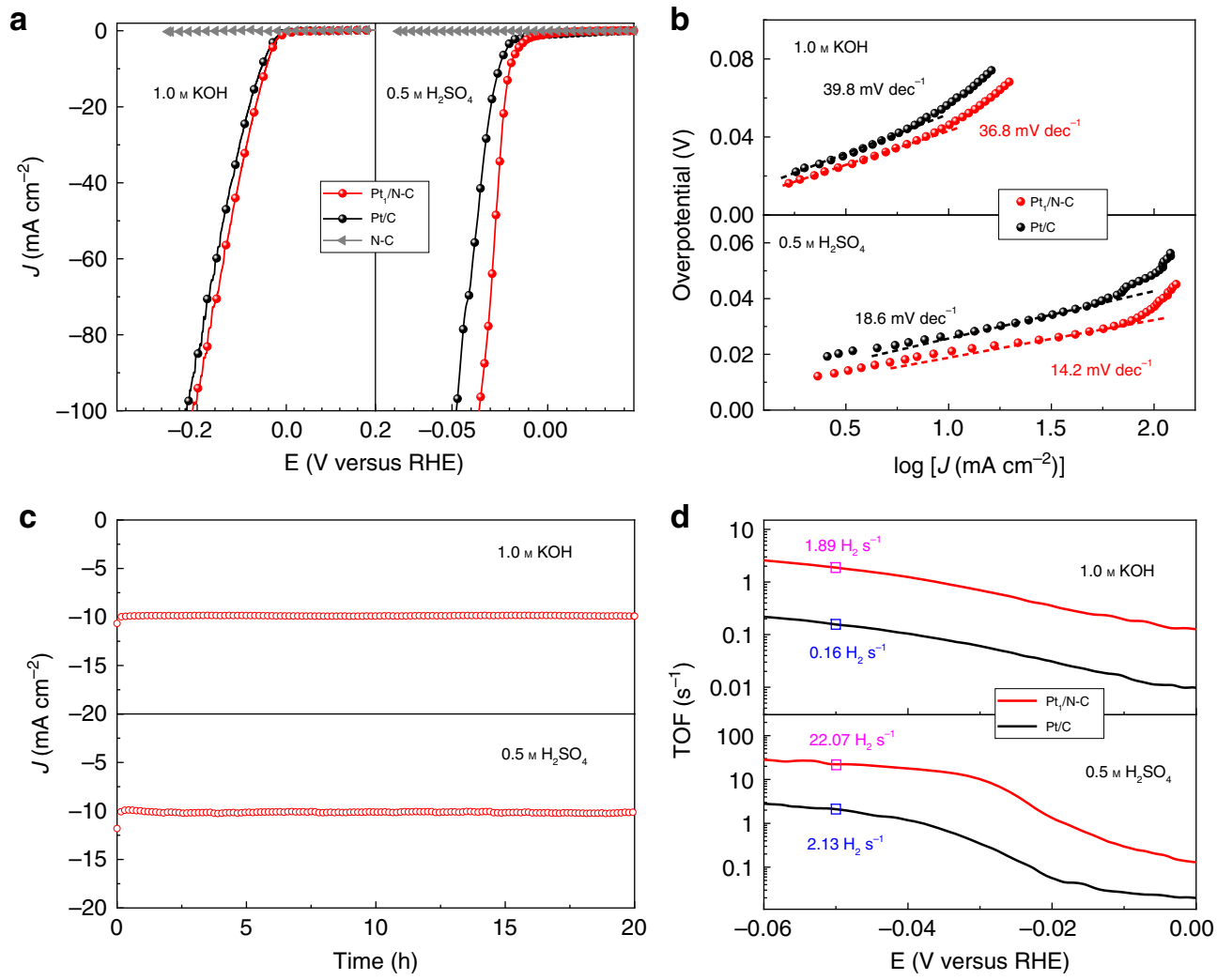

Fig. 4 Electrochemical analysis in both $1.0 \mathrm{~m} \mathbf{K O H}$ and $\mathbf{0 . 5} \mathbf{~ M ~}_{\mathbf{2}} \mathbf{S O}_{\mathbf{4}}$. a LSV curves of the $\mathrm{Pt}_{1} / \mathrm{N}-\mathrm{C}, \mathrm{Pt} / \mathrm{C}$ and N-C framework. J, current density; $E$, potential. b Tafel plots for $\mathrm{Pt}_{1} / \mathrm{N}-\mathrm{C}$ and $\mathrm{Pt} / \mathrm{C}$ electrocatalysts. c Durability test of $\mathrm{Pt}_{1} / \mathrm{N}-\mathrm{C}$. d TOF plots of the $\mathrm{Pt}_{1} / \mathrm{N}-\mathrm{C}$ and $\mathrm{Pt} / \mathrm{C}$ electrocatalysts. 


\section{Methods}

Synthesis of Uio-66- $\mathrm{NH}_{2}$ derived $\mathbf{N}-\mathrm{C}$ framework. At first, a mixture of $\mathrm{ZrCl}_{4}$ (37.76 mg, $0.162 \mathrm{mmol})$ and $\mathrm{H}_{2} \mathrm{BDC}-\mathrm{NH}_{2}(29.34 \mathrm{mg}, 0.162 \mathrm{mmol}$ ) was dissolved in $36 \mathrm{~mL}$ DMF plus $4.0 \mathrm{~mL} \mathrm{HAc}$ in a $60 \mathrm{~mL}$ glass vial, then sonicated for $1 \mathrm{~h}$. The vial was sealed and heated at $120^{\circ} \mathrm{C}$ for $24 \mathrm{~h}$ in an oven. The product was then centrifuged, washed with a mixture of methanol and DMF (volume ratio $=1: 4$ ), and then dried under vacuum at $90^{\circ} \mathrm{C}$. Then, powder of Uio-66- $\mathrm{NH}_{2}$ was placed in a tube furnace and heated to $700^{\circ} \mathrm{C}$ in a heating procedure of $2{ }^{\circ} \mathrm{C} / \mathrm{min}$ and preserved for $3 \mathrm{~h}$, under a flowing argon atmosphere. After cooling to room temperature, the black powder was collected and dispersed in $30 \mathrm{~mL} \mathrm{H}_{2} \mathrm{O}$ containing $0.2 \mathrm{~mol} \mathrm{HF}$ for $8 \mathrm{~h}$, and then centrifuged, washed with methanol and $\mathrm{H}_{2} \mathrm{O}$ (volume ratio $=1: 4)$ and dried under vacuum at $100^{\circ} \mathrm{C}$.

ALD preparation of $\mathbf{P t}_{1} / \mathbf{N}-\mathbf{C}$. Pt ALD was carried out on a viscous flow reactor (GEMSTAR-6 Benchtop ALD, Arradiance) by alternatively exposing to $\mathrm{MeCpPtMe}_{3}$ precursor and $\mathrm{O}_{2}(99.999 \%)$ at $150^{\circ} \mathrm{C}$. Ultrahigh purity $\mathrm{N}_{2}(99.999 \%)$ was used as the carrier gas at a flow rate of $200 \mathrm{~mL} / \mathrm{min}$. The Pt precursor was heated to $65^{\circ} \mathrm{C}$ to get a sufficient vapor pressure. The reactor inlets were held at $110^{\circ} \mathrm{C}$ to avoid any precursor condensation. The timing sequence was $80,120,60$, and 120 s for the MeCpPtMe exposure, $\mathrm{N}_{2}$ purge, $\mathrm{O}_{2}$ exposure, and $\mathrm{N}_{2}$ purge, respectively.

Material characterizations. The morphologies of the samples were examined by scanning electron microscopy and TEM on FEI-30 ESEM and JEOL-2100F systems at an accelerating voltage of $200 \mathrm{kV}$. EDS elemental mapping were obtained on a 26FEI Talos F200X device at $200 \mathrm{kV}$. HAADF-STEM, high-resolution TEM results were obtained on a JEM-ARM $200 \mathrm{~F}$ instrument at $200 \mathrm{kV}$. The concentration of $\mathrm{Pt}$ atoms was directly measured by ICP-OES (Optima 7300 DV, PerkinElmer). XPS measurements were carried out on an ESCALAB MKII instrument equipped with an $\mathrm{Mg} \mathrm{Ka}$ source $(\mathrm{h} v=1253.6 \mathrm{eV})$. The binding energy scale of all measurements was calibrated by referencing $\mathrm{C} 1 \mathrm{~s}$ to $284.5 \mathrm{eV}$. N K-edge XANES measurements were performed at the photoemission endstation at BL10B and BL12B beamlines of the National Synchrotron Radiation Laboratory (NSRL), China.

DRIFTS CO chemisorption measurements were performed on a Bruker IFS 66 v/s FTIR spectrometer equipped with a liquid nitrogen cooled HgCdTe (MCT) detector and a low-temperature reaction cell (Praying Mantis Harrick). The sample was loaded into the reaction cell and a background spectrum was collected. Next, the sample was exposed to $20 \% \mathrm{CO}$ in $\mathrm{Ar}$ at a flow rate of $30 \mathrm{~mL} / \mathrm{min}$ for $30 \mathrm{~min}$ to reach the $\mathrm{CO}$ saturation coverage. Then we purged the sample with Ar to remove the gas phase $\mathrm{CO}$ from the cell, and a series of DRIFT spectra were collected during both the CO-adsorption and the Ar-purgation process (256 scans, $4 \mathrm{~cm}^{-1}$ ).

Electrochemical measurements. All electrochemical measurements were carried out in a typical three-electrode electrochemical cell using graphite rod as the counter electrode and saturated $\mathrm{Ag} / \mathrm{AgCl}$ as the reference electrode. The catalyst ink ( $5 \mathrm{mg}$ catalyst $+765 \mu \mathrm{L}$ water $+200 \mu \mathrm{L}$ ethanol) was sonicated for $2 \mathrm{~h}$ to make the catalyst homogeneously dispersed, then $35 \mu \mathrm{L}$ Nafion solution $(5 \mathrm{wt} \%)$ was added to the ink and sonicated for $30 \mathrm{~min}$. The as-prepared ink $(10 \mu \mathrm{L})$ was loaded onto the glass carbon electrode to form the working electrode. Commercial 20\% Pt/ $\mathrm{C}$ catalyst was from Shanghai River Sen Electric Co. The sample loading was determined to be $\sim 0.25 \mathrm{mg} \mathrm{cm}^{-2}$. The HER activity measurement was carried out in high purity $\mathrm{H}_{2}$-saturated $0.5 \mathrm{M} \mathrm{H}_{2} \mathrm{SO}_{4}(\mathrm{pH} 0.1)$ and $1.0 \mathrm{M} \mathrm{KOH} \mathrm{(pH} \mathrm{13.8),} \mathrm{using}$ linear sweep voltammetry with a scan rate of $5 \mathrm{mV} \mathrm{s}^{-1}$. The HER stability was evaluated by measuring amperometric $\mathrm{i}-\mathrm{t}$ curve under the overpotential $(J=$ $\left.10 \mathrm{~mA} \mathrm{~cm}^{-2}\right)$. The potentials were calibrated to RHE using Pt mesh as working electrode (Supplementary Fig. 22):

$$
\begin{gathered}
\mathrm{E}\left(\mathrm{RHE}, 0.5 \mathrm{M} \mathrm{H}_{2} \mathrm{SO}_{4}\right)=\mathrm{E}(\mathrm{Ag} / \mathrm{AgCl})+0.204 \mathrm{~V} \\
\mathrm{E}(\mathrm{RHE}, 1.0 \mathrm{M} \mathrm{KOH})=\mathrm{E}(\mathrm{Ag} / \mathrm{AgCl})+1.012 \mathrm{~V}
\end{gathered}
$$

Operando XAFS measurements. The $\mathrm{Pt}_{2}$-edge $(11,564 \mathrm{eV})$ XAFS spectra were measured at the 1W1B beamline of Beijing Synchrotron Radiation Facility (BSRF), China. The storage ring of BSRF was operated at $2.5 \mathrm{GeV}$ with a maximum electron current of $250 \mathrm{~mA}$. The hard X-ray was monochromatized with a Si (111) doublecrystal monochromator and detuned by $30 \%$ to remove harmonics. Operando XAFS measurements were performed in the fluorescence mode. Position of the absorption edge $\left(E_{0}\right)$ was calibrated using Pt foil.

XAFS data analysis. The acquired EXAFS data were processed according to standard procedures using the ATHENA module implemented in the IFEFFIT software packages ${ }^{40}$. The $k^{2}$-weighted $\chi(\mathrm{k})$ data in the $k$-space ranging from 3.0 to $11.0 \AA^{-1}$ were Fourier-transformed to real $(R)$ space using hanning windows $\left(\mathrm{d} k=1.0 \AA^{-1}\right)$ to separate the EXAFS contributions from different coordination shells. To obtain the detailed structural parameters around the Pt atom in the asprepared samples, quantitative curve fittings were carried out for the Fouriertransformed $k^{2} \chi(\mathrm{k})$ in R-space using the ARTEMIS module of IFEFFIT. Effective backscattering amplitudes $\mathrm{F}(k)$ and phase shifts $\Phi(k)$ of all fitting paths were calculated with the ab initio code FEFF8.0. For the $\mathrm{Pt}_{1} / \mathrm{N}-\mathrm{C}$ samples, a $k$-range of $3.0 \sim 11.0 \AA^{-1}$ was used and curve fittings were carried out in R-space within an $\mathrm{R}$ range of $(1.0,2.1) \AA$ for $k^{2}$-weighted $\chi(k)$ functions. The number of independent points is given by

$$
N_{\text {ipt }}=2 \Delta k \times \Delta R / \pi=2 \times(11.0-3.0) \times(2.1-1.0) / \pi=6
$$

As for the sample under various conditions, the Fourier-transformed curves all showed a single prominent coordination peak at $\sim 1.6 \AA$ assigned to the $\mathrm{Pt}-\mathrm{C} / \mathrm{N}$ coordination. For the ex situ $\mathrm{Pt}_{1} / \mathrm{N}-\mathrm{C}$ sample, two separate Pt-C and Pt-N scattering paths were included for fitting. The combination of oxidation state and EXAFS fittings demonstrate that four-coordinate Pt with three Pt-C bonds and one Pt-N bond, is most reasonable for ex situ sample, as well as the open circuit and $+0.5 \mathrm{~V}$ sample. The FT peak intensity of the sample under $+0.15 \mathrm{~V}$ declines by $13 \%$, which may arise from the $\mathrm{Pt}-\mathrm{C} / \mathrm{N}$ bonds breaking, together with an additional Pt-O coordination from $\mathrm{H}_{2} \mathrm{O}$ adsorption. Thus, the scattering paths of Pt-C/N and $\mathrm{Pt}-\mathrm{O}$ were considered. Although under $-0.07 \mathrm{~V}$, the FT peak intensity further declines by $35 \%$, which is ascribed to the dissociation of the adsorbed $\mathrm{H}_{2} \mathrm{O}$ followed by $\mathrm{H}$ adsorption on $\mathrm{Pt}$, leading to only $\mathrm{Pt}-\mathrm{C} / \mathrm{N}$ path considered for EXAFS fitting. It should be mentioned that under operating conditions, the structures derived from EXAFS fitting may correspond to the species that are most present in the rate-limiting step. Hence, under $+0.15 \mathrm{~V}$, the water absorbed on $\mathrm{Pt}_{1}-\mathrm{C}_{2}$ or $\mathrm{Pt}_{1}$ $\mathrm{C}_{1} \mathrm{~N}_{1}$ structures $\left(\mathrm{H}_{2} \mathrm{O}-\mathrm{Pt}_{1}-\mathrm{C}_{2}, \mathrm{H}_{2} \mathrm{O}-\mathrm{Pt}_{1}-\mathrm{C}_{1} \mathrm{~N}_{1}\right)$ are considered because the reaction is limited by dissociation of the absorbed $\mathrm{H}_{2} \mathrm{O}$. Although under $-0.07 \mathrm{~V}$, the ratelimiting step is Heyrovsky step determined by the Tafel slope, leading to highcoverage absorbed $\mathrm{H}$ keep intact on $\mathrm{Pt}$ from desorption, and thus $\mathrm{H}-\mathrm{Pt}_{1}-\mathrm{C}_{2}$ and $\mathrm{H}-$ $\mathrm{Pt}_{1}-\mathrm{C}_{1} \mathrm{~N}_{1}$ structures are considered.

During curve fittings, the Debye-Waller factors $\left(\sigma^{2}\right)$ and bond length $(R)$ were treated adjustably for all samples in all paths. For the ex situ sample, $N$ and $R$ were treated as adjustable parameters for both Pt-N and Pt-C shells, whereas their $\sigma^{2}$ and $\Delta E_{0}$ were set equal in order to reduce the number of fitting parameters. Thus, the number of the adjustable parameters for the ex situ sample is $N_{\text {para }}=6 \leq N_{\text {ipt. }}$ For the $+0.50 \mathrm{~V}$ sample, $\Delta E_{0}$ of the Pt-C/N path was set equal to that of the ex situ sample, other parameters were treated adjustably. $N_{\text {para }}=6$. For the $+0.15 \mathrm{~V}$ and $-0.07 \mathrm{~V}$ sample, $\Delta E_{0}$ of the Pt-C/N path were set equal to that of the ex situ sample. In addition, the fitting strategy of the $0.15 \mathrm{~V}-\mathrm{pH} 1$ sample was identical to $-0.07 \mathrm{~V}$ sample; while the fitting strategy of $+0.15 \mathrm{~V}$-pH14 sample was identical to that of the $+0.15 \mathrm{~V}$ sample. Using these strategies, all generated $R$ factors are smaller than 0.01 , indicating excellent quality.

Computational methods. All theoretical calculations were performed using Vienna ab initio simulation packages ${ }^{41}$. The exchange-correlation interaction was described by the generalized gradient approximation with the Perdew-Burke-Ernzerhof functional ${ }^{42}$. A two-dimensional carbon/nitrogen matrix supercell was built on a $8 \times 8$ unit cell for the four-coordinate $\mathrm{Pt}_{1}-\mathrm{C}_{3} \mathrm{~N}_{1}$ system, to simulate the two-coordinate $\mathrm{Pt}$ intermediate, we modulated the pristine graphene surface with $16\left(\mathrm{Pt}_{1}-\mathrm{C}_{2}-1, \mathrm{Pt}_{1}-\mathrm{C}_{1} \mathrm{~N}_{1}-1\right)$ and $15\left(\mathrm{Pt}_{1}-\mathrm{C}_{2}-2, \mathrm{Pt}_{1}-\mathrm{C}_{1} \mathrm{~N}_{1}-2\right)$ carbon/ nitrogen atoms removed. The effects of the varying hydrogenation degrees of the dangling carbon atoms around the defects have been investigated (Supplementary Fig. 23). Considering that these dangling carbon atoms would undergo hydrogenation during electrochemical reduction, thus they were saturated with $\mathrm{H}$ atoms in the main text. The plane wave cutoff was set to $500 \mathrm{eV}$, with the convergence of energy and force set to $1 \times 10^{-5}$ and $0.01 \mathrm{eV}^{-1}$, respectively. To avoid the interaction between two adjacent layers the vacuum thickness was set to $15 \AA$. The Brillouin zone was sampled by a $5 \times 5 \times 1 k$-point grid with the Monkhorst-Pack scheme for structural optimization and a $10 \times 10 \times 1 k$-point grid for electronic structure calculations for all systems. The solvent effects were considered by using the Poisson-Boltzmann implicit solvent model with the dielectric constant set to be 78.4 for solvent water ${ }^{43}$.

\section{Data availability}

The data supporting the findings of this study are available from the corresponding author upon reasonable request.

Received: 21 October 2019; Accepted: 7 February 2020; Published online: 25 February 2020

\section{References}

1. Malta, G. et al. Identification of single-site gold catalysis in acetylene hydrochlorination. Science 355, 1399-1403 (2017).

2. Fei, H. et al. General synthesis and definitive structural identification of $\mathrm{MN}_{4} \mathrm{C}_{4}$ single-atom catalysts with tunable electrocatalytic activities. Nat. Catal. 1, 63-72 (2018)

3. Zhao, L. et al. Cascade anchoring strategy for general mass production of high-loading single-atomic metal-nitrogen catalysts. Nat. Commun. 10, 1278 (2019)

4. Zheng, X. et al. Theory-driven design of high-valence metal sites for water oxidation confirmed using in situ soft X-ray absorption. Nat. Chem. 10, 149-154 (2018) 
5. Pan, $\mathrm{Y}$. et al. Design of single-atom $\mathrm{Co}-\mathrm{N}_{5}$ catalytic site: a robust electrocatalyst for $\mathrm{CO}_{2}$ reduction with nearly $100 \% \mathrm{CO}$ selectivity and remarkable stability. J. Am. Chem. Soc. 140, 4218-4221 (2018).

6. Qiao, B. et al. Single-atom catalysis of $\mathrm{CO}$ oxidation using $\mathrm{Pt}_{1} / \mathrm{FeO}_{\mathrm{x}}$. Nat . Chem. 3, 634-641 (2011).

7. Chen, Y. et al. Single-atom. Catalysts: Synth. Strateg. Electrochem. Appl. Joule 2, 1242-1264 (2018).

8. Wang, A., Li, J. \& Zhang, T. Heterogeneous single-atom catalysis. Nat. Rev. Chem. 2, 65-81 (2018).

9. Shan, J., Li, M., Allard, L. F., Lee, S. \& Flytzani-Stephanopoulos, M. Mild oxidation of methane to methanol or acetic acid on supported isolated rhodium catalysts. Nature 551, 605-608 (2017).

10. Zhang, J. Q. et al. Single platinum atoms immobilized on an MXene as an efficient catalyst for the hydrogen evolution reaction. Nat. Catal. 1, 985-992 (2018)

11. Yang, H. B. et al. Atomically dispersed $\mathrm{Ni}(\mathrm{I})$ as the active site for electrochemical $\mathrm{CO}_{2}$ reduction. Nat. Energy 3, 140-147 (2018).

12. Chung, H. T. et al. Direct atomic-level insight into the active sites of a highperformance PGM-free ORR catalyst. Science 357, 479-484 (2017).

13. Geng, Z. et al. Achieving a record-high yield rate of $120.9 \mu \mathrm{g}_{\mathrm{NH} 3} \mathrm{mg}^{-1}$ cat. $\mathrm{h}^{-1}$ for $\mathrm{N}_{2}$ electrochemical reduction over Ru single-atom catalysts. Adv. Mater. 30, 1803498 (2018)

14. Qu, Y. et al. Direct transformation of bulk copper into copper single sites via emitting and trapping of atoms. Nat. Catal. 1, 781-786 (2018).

15. Liu, W. et al. Single-site active cobalt-based photocatalyst with a long carrier lifetime for spontaneous overall water splitting. Angew. Chem. Int. Ed. 56, 9312-9317 (2017)

16. O'Connor, N. J., Jonayat, A. S. M., Janik, M. J. \& Senftle, T. P. Interaction trends between single metal atoms and oxide supports identified with density functional theory and statistical learning. Nat. Catal. 1, 531-539 (2018).

17. Li, H. et al. Synergetic interaction between neighbouring platinum monomers in $\mathrm{CO}_{2}$ hydrogenation. Nat. Nanotechnol. 13, 411-417 (2018).

18. Zhao, S. et al. Ultrathin metal-organic framework nanosheets for electrocatalytic oxygen evolution. Nat. Energy 1, 16184 (2016).

19. Zhang, B. et al. Homogeneously dispersed multimetal oxygen-evolving catalysts. Science 352, 333-337 (2016).

20. Greiner, M. T. et al. Free-atom-like d states in single-atom alloy catalysts. Nat. Chem. 10, 1008-1015 (2018)

21. Cao, L. et al. Identification of single-atom active sites in carbon-based cobalt catalysts during electrocatalytic hydrogen evolution. Nat. Catal. 2, 134-141 (2018).

22. Allian, A. D. et al. Chemisorption of $\mathrm{CO}$ and mechanism of $\mathrm{CO}$ oxidation on supported platinum nanoclusters. J. Am. Chem. Soc. 133, 4498-4517 (2011).

23. Ding, K. et al. Identification of active sites in $\mathrm{CO}$ oxidation and water-gas shift over supported Pt catalysts. Science 350, 189-192 (2015).

24. Borchert, H. et al. Ligand-capped Pt nanocrystals as oxide-supported catalysts: FTIR spectroscopic investigations of the absorption and oxidation of CO. Angew. Chem. Int. Ed. 46, 2923-2926 (2007).

25. Zhang, $\mathrm{Z}$. et al. Thermally stable single atom $\mathrm{Pt} / \mathrm{m}-\mathrm{Al}_{2} \mathrm{O}_{3}$ for selective hydrogenation and CO oxidation. Nat. Commun. 8, 16100 (2017).

26. Wang, X. et al. Uncoordinated amine groups of metal-organic frameworks to anchor single Ru sites as chemoselective catalysts toward the hydrogenation of quinoline. J. Am. Chem. Soc. 139, 9419-9422 (2017).

27. Tao, $\mathrm{H}$. et al. Nitrogen fixation by Ru single-atom electrocatalytic reduction. Chem 5, 204-214 (2019).

28. Yang, H. B. et al. Identification of catalytic sites for oxygen reduction and oxygen evolution in $\mathrm{N}$-doped graphene materials: development of highly efficient metal-free bifunctional electrocatalyst. Sci. Adv. 2, e1501122 (2016).

29. Wang, J. et al. Design of N-coordinated dual-metal sites: a stable and active Ptfree catalyst for acidic oxygen reduction reaction. J. Am. Chem. Soc. 139, 17281-17284 (2017)

30. Jiao, Y., Zheng, Y., Davey, K. \& Qiao, S. Z. Activity origin and catalyst design principles for electrocatalytic hydrogen evolution on heteroatom-doped graphene. Nat. Energy 1, 16130 (2016).

31. Chen, P. et al. Atomically dispersed iron-nitrogen species as electrocatalysts for bifunctional oxygen evolution and reduction reactions. Angew. Chem. Int. Ed. 56, 610-614 (2017)

32. $\mathrm{Wu}, \mathrm{K}$. et al. Porphyrin-like Fe- $\mathrm{N}_{4}$ sites with sulfur adjustment on hierarchical porous carbon for different rate-determining steps in oxygen reduction reaction. Nano Res. 11, 6260-6269 (2018).

33. Dai, S. et al. Platinum-trimer decorated cobalt-palladium core-shell nanocatalyst with promising performance for oxygen reduction reaction. Nat. Commun. 10, 440 (2019).

34. Cheng, N. et al. Platinum single-atom and cluster catalysis of the hydrogen evolution reaction. Nat. Commun. 7, 13638 (2016).

35. Ledezma-Yanez, I. et al. Interfacial water reorganization as a pH-dependent descriptor of the hydrogen evolution rate on platinum electrodes. Nat. Energy 2, 17031 (2017).
36. Sheng, W. C. et al. Correlating hydrogen oxidation and evolution activity on platinum at different $\mathrm{pH}$ with measured hydrogen binding energy. Nat. Commun. 6, 5848 (2015).

37. Oudenhuijzen, M. K., Bitter, J. H. \& Koningsberger, D. C. The nature of the $\mathrm{Pt}-\mathrm{H}$ bonding for strongly and weakly bonded hydrogen on platinum. A XAFS spectroscopy study of the Pt-H antibonding shaperesonance and Pt-H EXAFS J. Phys. Chem. B 105, 4616-4622 (2001).

38. Nørskov, J. K. et al. Trends in the exchange current for hydrogen evolution. J. Electrochem. Soc. 152, J23-J26 (2005).

39. Mahmood, J. et al. An efficient and $\mathrm{pH}$-universal ruthenium-based catalyst for the hydrogen evolution reaction. Nat. Nanotechnol. 12, 441-446 (2017).

40. Newville, M. IFEFFIT: interactive XAFS analysis and FEFF fitting. $J$. Synchrotron Radiat. 8, 322-324 (2001).

41. Kresse, G. \& Furthmuller, J. Efficient iterative schemes for ab initio totalenergy calculations using a plane-wave basis set. Phys. Rev. B 54, 11169-11186 (1996).

42. Perdew, J. P., Burke, K. \& Ernzerhof, M. Generalized gradient approximation made simple. Phys. Rev. Lett. 77, 3865-3868 (1996).

43. Mathew, K., Sundararaman, R., Letchworth-Weaver, K., Arias, T. A. \& Hennig, R. G. Implicit solvation model for density-functional study of nanocrystal surfaces and reaction pathways. J. Chem. Phys. 140, 084106 (2014).

\section{Acknowledgements}

This research was supported by China Ministry of Science and Technology under Contract of 2017YFA0208300 and 2017YFA0402800, the National Natural Science Foundation of China (grants no. 21471143, 21533007, 11621063) and the Fundamental Research Funds for the Central Universities (KY2310000020, WK2340000076, WK2060030029), and Youth Innovation Promotion Association CAS (CX2310000091) We thank NSRL, BSRF, and SSRF for the synchrotron beam time.

\section{Author contributions}

T.Y. developed the idea and designed experiments. S.F., X.K.L., W.L., D.H.W., W.Z., and S.Q.W. performed the catalyst synthesis and characterizations, XAFS measurement, and electrochemical experiments, collected, and analyzed the data. S.F., J.G., and J.L.L. performed ALD synthesis. X.R.Z. and Y.F.L. conducted and discussed the theoretical calculations. S.F. and Y.L. performed the aberration-corrected STEM characterization. S.F and T.Y. co-wrote the paper. All authors discussed the results and commented on the manuscript.

\section{Competing interests}

The authors declare no competing interests.

\section{Additional information}

Supplementary information is available for this paper at https://doi.org/10.1038/s41467020-14848-2.

Correspondence and requests for materials should be addressed to T.Y.

Peer review information Nature Communications thanks Bin Liu and the other, anonymous, reviewer(s) for their contribution to the peer review of this work. Peer reviewer reports are available.

Reprints and permission information is available at http://www.nature.com/reprints

Publisher's note Springer Nature remains neutral with regard to jurisdictional claims in published maps and institutional affiliations.

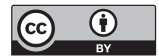

Open Access This article is licensed under a Creative Commons Attribution 4.0 International License, which permits use, sharing, adaptation, distribution and reproduction in any medium or format, as long as you give appropriate credit to the original author(s) and the source, provide a link to the Creative Commons license, and indicate if changes were made. The images or other third party material in this article are included in the article's Creative Commons license, unless indicated otherwise in a credit line to the material. If material is not included in the article's Creative Commons license and your intended use is not permitted by statutory regulation or exceeds the permitted use, you will need to obtain permission directly from the copyright holder. To view a copy of this license, visit http://creativecommons.org/ licenses/by/4.0/.

(C) The Author(s) 2020 